\title{
Treatment of Multi-Tonnage Manganese-Containing Waste Water Using Vermiculite
}

\author{
Vera Matveeva', Aleksandr Danilov' ${ }^{1 *}$, Maria Pashkevich \\ 1 Geoecology Department, Saint-Petersburg Mining University, 2, 21st Line, Saint-Petersburg, 199106, Russia \\ * Corresponding authot's e-mail: aleksandrsdanilov@gmail.com
}

\begin{abstract}
The article presents the results of field and laboratory studies on the state of surface waters in the impact zone of one of the largest mining enterprises of the Russian Federation, i.e. Kovdor Mining and Processing Combine. On the basis of the data from the monitoring studies, the patterns of migration and transformation of manganese in the system of wastes of enrichment - surface water - are revealed. In order to solve the existing environmental problem, an effective method of treating sewage from manganese using organic sorbent based on vermiculite is proposed. The results of laboratory tests of the sorbent are described depending on the method of its modification, as well as on the composition and properties of the purified water. The proposed method of sewage treatment will reduce the negative impact of the company on surface water, thereby improving the ecological situation in the study area and improving the quality of life of the local population.
\end{abstract}

Keywords: sewage, hydrochemical anomaly, manganese, sorbent, vermiculite, tailing dumps, negative impact.

\section{INTRODUCTION}

As a result of mining and processing of minerals in the territory of the Russian Federation, about 1 billion cubic meters of sewage water enter the water bodies annually. Sewage is characterized by an increased content of pollutants, including heavy metals. The discharge of largetonnage sewage of mining enterprises adversely affects all the components of the natural environment and leads to irreversible environmental consequences. The chemical contamination of the hydrosphere, which can migrate over long distances, is of particular concern.

The aim of the research was to study the causes of the formation of a high-contrast manganese hydrochemical anomaly, the spatial distribution of which indicates its man-caused origin, and the development of water protection measures aimed at reducing the negative impact of the source of pollution.

The object of research was the Kovdor ore mining and processing enterprise, one of the larg- est producers of iron ore and apatite concentrates in Russia, as well as the only producer of baddeleyite concentrate in the world.

The enterprise is located in the northern part of the country, on the territory of the Kola Peninsula, which is characterized by low selfcleaning ability of natural ecosystems and exacerbates the existing environmental problems, which include the pollution of surface waters as a result of organized wastewater discharge and infiltration of surface runoff from the surface of technogenic massifs.

The enterprise's activity leads to an annual water disposal of 50 million cubic meters, 20 million cubic meters of which come to surface waters from the tailing site.

In this regard, the primary goals of the studies were hydrochemical monitoring in the zone of influence of the enterprise, assessment of the level of man-caused stress on water bodies and reduction of the negative impact by developing a method for wastewater treatment. 


\section{MATERIALS AND METHODS}

Long-term results of monitoring studies have shown that among the metals observed in the formed hydrochemical flows of the Kovdor district, manganese is the greatest danger due to abnormally high concentrations. This metal enters into water together with sewage tailings, so the priority objectives of the study were the identification of external and internal sources of receipt of manganese compounds in the tailings and evaluation of the behavior of manganese in the thickness impounded tailings.

Manganese is not the target extractable component of the investigated deposit, but its content in complex ferruginous and in low-iron apatite-carbonate ores reaches $0.40-0.52$ percent in terms of $\mathrm{MnO}$.

The analysis of the waste showed that pulp with a manganese content of 0.1 percent comes into the tailing dump, most of it is in an insoluble state in the composition of mineral particles larger than 2 microns (Figure 1). In the pulp filtrate, the manganese content was $0.02 \mathrm{mg} / \mathrm{dm}^{3}$ and corresponded to its concentration in the recycled water, whereas in the tailings water filtration, the concentration of dissolved manganese reached already $1.4 \mathrm{mg} / \mathrm{dm}^{3}$. A quantitative chemical analysis of solid and liquid samples was carried out by atomic absorption spectrometry using the Shamadzu AA-7000 analyzer.

In the course of the scientific and practical research, a regular change in the concentration of dissolved manganese was recorded as a function of the change in the hydrogen index (pH). Therefore, manganese was in an insoluble state in the composition of the pulp and the surface layers of waste tailings at $\mathrm{pH} 9$. However, a decrease in $\mathrm{pH}$ to 8 in the filtration water contributed to a significant increase in dissolved manganese. Simulation of the leaching process under laboratory conditions showed that a change in the hydrogen index per unit leads to an increase in mobile forms of manganese by 20 percent. Under natural conditions, the decrease in $\mathrm{pH}$ is facilitated by the precipitation of atmospheric precipitation and the mixing of natural and process waters in the tailing site.

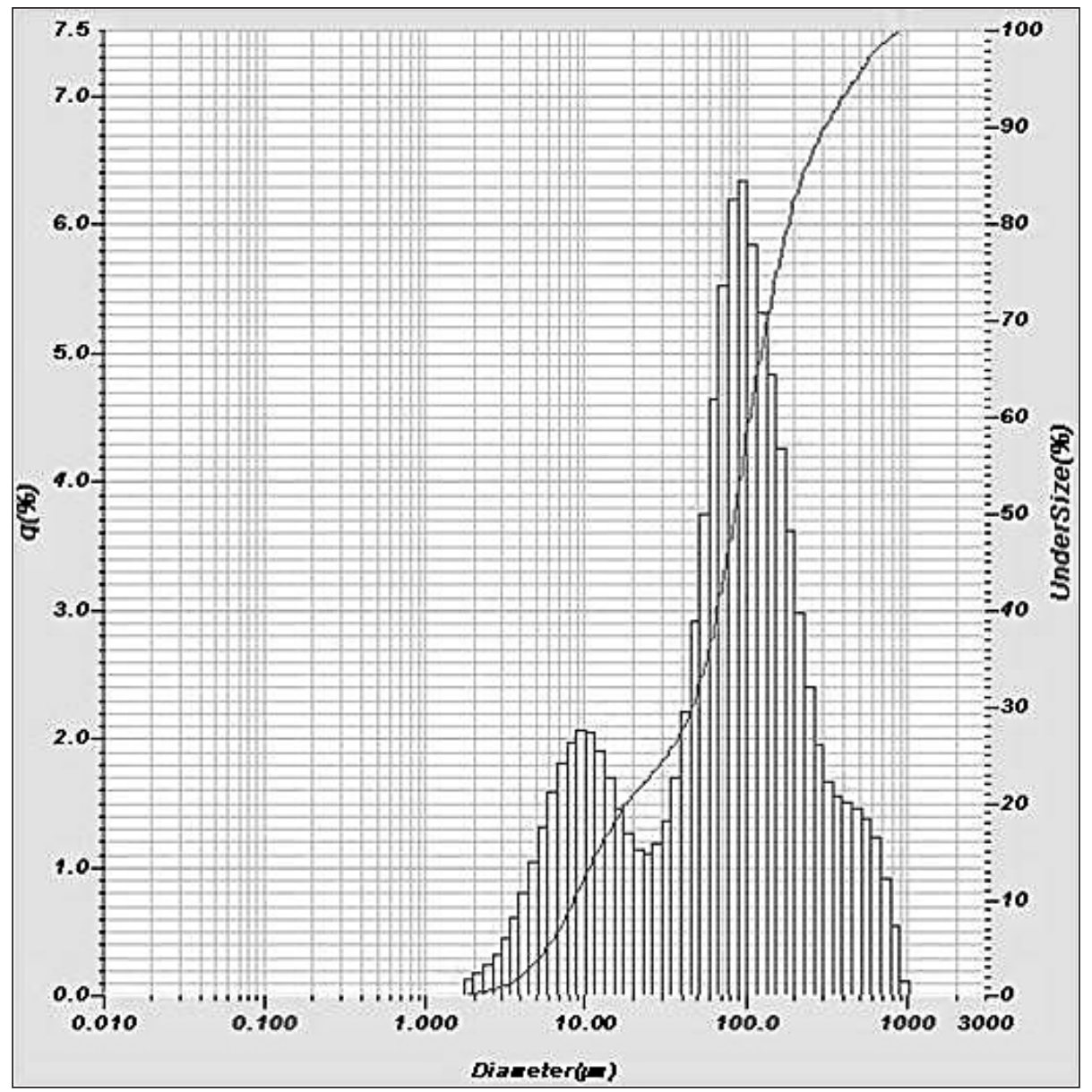

Figure 1. The results of the granulometric analysis of tailings 
According to the Purbe diagram, the redox environment also affects the transition of manganese from an insoluble form to a soluble one. An analysis of the vertical distribution of manganese in stale tails has shown that the content of manganese increases in the lower horizons where anoxic conditions are observed (Table 1).

Considering the amount of waste that is stored annually in the tailing dump, which reaches 8 million cubic meters, the ore and the products of their processing lead to the appearance of manganese in the surface waters. As a result of the processing of mineral raw materials (grinding, flotation, etc.), manganese, which is in a bound state in minerals, becomes more sensitive to the changes in environmental conditions, in particular, to a change in the acid-base and oxidation-reduction conditions. On the basis of the field and laboratory studies, it is established that the main form of migration of manganese is the $\mathrm{Mn}^{2+}$ ion, which is washed out of the tailings by filtration waters for the following reasons:

- Fine-fractional grinding of rocks.

- Anoxic conditions in the thickness of stale tails and swampiness of the adjacent territory.

- "Flushing" of tails with acidified waters of surface runoff and atmospheric precipitation.

- Microbiological processes,
The process of manganese removal from the sedimentation tank has clear seasonal differences with peaks during the winter periods, which is associated with a change in the ratio between the surface and underground runoff, an increase in the "oxygen-free" runoff mode due to snow and ice, and a decrease in self-cleaning processes (Figure 2).

The analysis of the existing methods pertaining to the treatment of manganese-containing waters allowed to distinguish the following methods of purification: aeration under pressure with subsequent filtration, chemical oxidation followed by precipitation and filtration, use of ion-exchange reagents, sorption.

Taking into account the large tonnage of sewage of the plant's tailing dump (2200-2800 cubic meters per hour) and the range of manganese concentrations $\left(0.26-1.38 \mathrm{mg} / \mathrm{dm}^{3}\right)$, the introduction of the first three methods will lead to high economic costs and (or) low indicators cleaning.

The use of artificial sorbents is also economically unjustified in the current situation.

At the same time, the analysis of modern methods of water treatment used in the mining industry has shown that the sorption methods based on natural sorbents are now widely used for wastewater treatment.

Table 1. Mn content in various horizons of the waste enrichment waste of the Kovdor ore mining and processing enterprise, mass percentages

\begin{tabular}{|c|c|c|c|c|c|}
\hline \multirow{2}{*}{ Element } & \multicolumn{5}{|c|}{ Horizons } \\
\hline & Лx-1 (5 м) & Лx-2 (10 м) & Лx-3 (15 м) & Лx-4 (20 м) & Лх $-5(25$ м) \\
\hline $\mathrm{Mn}$ & 0.11 & 0.11 & 0.12 & 0.13 & 0.15 \\
\hline
\end{tabular}

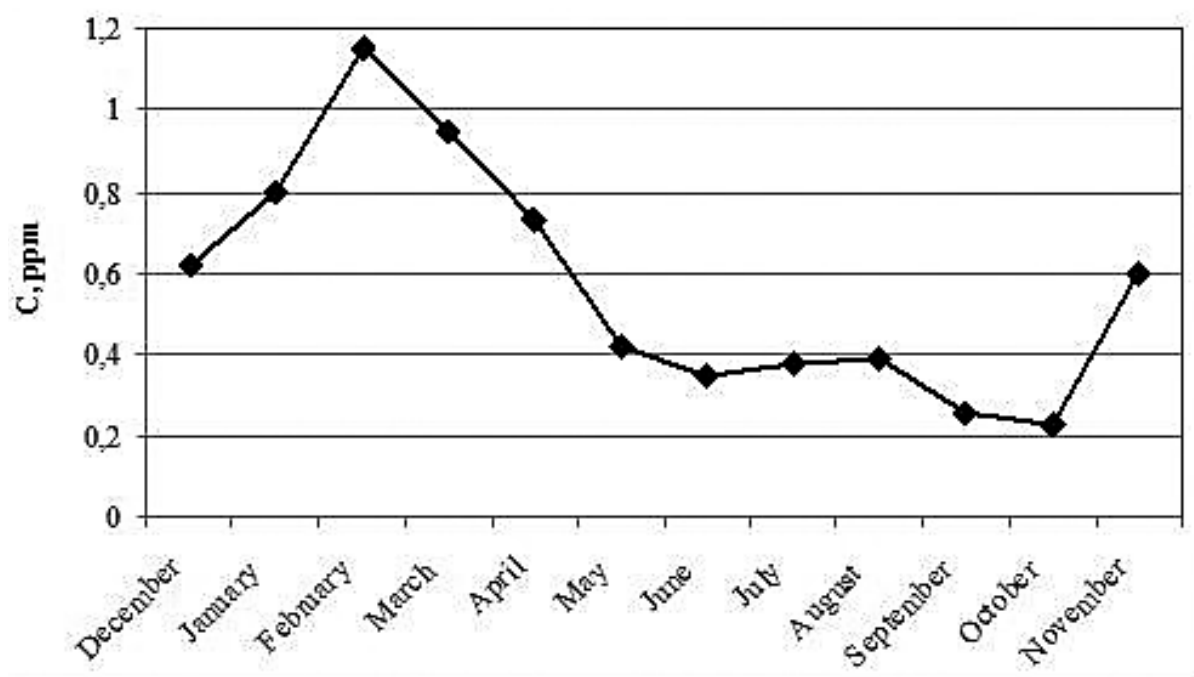

Figure 2. Seasonal dynamics of manganese content in the treated wastewater of the enrichment complex 
However, in most cases, the use of natural sorbents is restrained because of the lack of a wide range, which is a consequence of insufficient knowledge of their physicochemical properties [Valente et al. 2012].

In order to address the issue of protecting surface waters, a detailed study of the mineral resource base of the Kovdor district was carried out to identify available and widespread natural sorbents. A natural mineral - vermiculite - characterized by a sharp selectivity with respect to cations of alkaline, alkaline earth and heavy metals was attributed to such sorbents [Alexandre-Franco et al. 2011]. In general, vermiculites belong to magnesia-ferruginous micas with a high degree of hydration [Sis 2014, Da Fonseca et al. 2006]. Technically, vermiculite is a microporous sorbent with variable pore size during adsorption. In addition to the primary microporosity due to the crystal structure, secondary, mostly transitional pores, formed by gaps between the contacting particles are characteristic for vermiculite [Buzuku et al. 2015]. The predominant type of sorption for vermiculite is cation exchange. The main reason for the cation-exchange capacity of vermiculite is the heterovalent isomorphism of its structure. Investigation of the properties of vermiculite indicated the prospects of its use in purification of manganese-containing wastewater. In addition, it should be noted that the vermiculite deposit is located in the territory of the Kovdor region, in the distance of three kilometers from the investigated deposit of magnetite-apatite-baddeleyite ores.

Representative mineral samples were selected at this deposit to conduct laboratory tests of vermiculite.

\section{RESULTS}

In order to assess the sorption properties of vermiculite in relation to manganese (II), the question of its ore preparation was studied first. The layered structure of vermiculite requires a special technology of crushing which is different from most other mineral objects,. The technological schemes for obtaining vermiculite concentrate for large and medium crushing of ore use jaw crushers, whereas for the small variant, hammers are utilized. This is due to the fact that industrial consumers use mainly expanded vermiculite, and when crushing vermiculite in a hammer mill, it is destroyed mainly across the layers of the sample. Therefore, when choosing the crushing plants of the final stage of crushing in industry, they are guided by impact machines. It could be assumed that in order to use the original vermiculite as a natural sorbent, it is advisable to carry out its final disintegration in grinders with cutting and (or) shearing forces, which will lead to layer-by-layer destruction of the samples [Chanturia et al. 2014, Vaisberg et al. 2014].

The preparation of laboratory samples of Kovdor vermiculite was carried out in two stages. The first stage of crushing vermiculite with a size of $150-200 \mathrm{~mm}$ was carried out in the hammer mill SMD-112. At the output, a material 3-5 mm in size was obtained. The second stage of crushing vermiculite was carried out in a rotary type crusher IKA MF10 Basic with a cutting nozzle intended for crushing dry medium-hard and soft materials of organic and inorganic origin. In order to carry out the experiment on model solutions, an industrial vermiculite sample was used, crushed across the layers, and laboratory samples of the same size, ground by layer. It is known that the thermal treatment of layered silicates, including industrial vermiculite concentrate, leads to an increase in their porosity and specific surface. Following this, part of the sample weights of the industrial vermiculite concentrate sample was heat treated in a muffle furnace at temperatures of 300 and $600^{\circ} \mathrm{C}$ for two hours.

A static method was used to determine the quantitative characteristics of the sorption process on vermiculite. Weighed $0.5 \mathrm{~g}$ of material were mixed on a magnetic stirrer for 10 minutes with $350 \mathrm{~cm}^{3}$ of a model solution with a manganese concentration of $1 \mathrm{mg} / \mathrm{dm}^{3}$. After sorption, the solutions were filtered through a "red tape" of the paper filter. The extraction of manganese (II) cations is shown in Table 2.

Table 2 shows that the maximum degree of manganese (II) recovery is observed when using vermiculite samples without layer heat-treatment, layered in a laboratory rotor crusher.

On this basis, all further studies were carried out on laboratory samples prepared by this route.

As it is known, crushing of the sorption material leads to an increase in the contact area with the water to be purified and, as a result, significantly increases the amount of sorption of pollutants from the solution. Therefore, the next stage of laboratory studies was the determination of the effect of the particle size of vermiculite on the purification efficiency. The results of the analysis showed that the degree of extraction of manganese cations increases with a smaller grain of vermiculite (Table 3). 
Table 2.The recovery of manganese cations (II) from model solutions

\begin{tabular}{|l|c|c|c|c|}
\hline \multicolumn{1}{|c|}{ Final crushing method } & Hammer crusher & Hammer crusher & Hammer crusher & $\begin{array}{c}\text { Impact crusher with } \\
\text { cutting nozzle }\end{array}$ \\
\hline Heat treatment & absent & $300{ }^{\circ} \mathrm{C}$ & $600{ }^{\circ} \mathrm{C}$ & absent \\
\hline $\begin{array}{l}\text { The recovery of manganese } \\
\text { ion (II) on vermiculite, } \%\end{array}$ & 51 & 52 & 68 & 87 \\
\hline
\end{tabular}

Studying the kinetics of sorption showed that equilibrium in the system using samples of size $0.315-0.500 \mathrm{~mm}$ and $0.5-1.0 \mathrm{~mm}$ occurs in 0.5 hours, $1-2 \mathrm{~mm}$ - in 1 hour (Figure 3 ). Beforehand, the balance in the system using a fraction of $0.125-0.315 \mathrm{~mm}$ in size occurs in 20 minutes. In addition, experiments have shown that the rate of sorption of manganese (II) on vermiculite is maximal in the first minutes of contact.

According to the obtained experimental data, the adsorption of manganese cations on vermiculite from model solutions with initial manganese (II) concentrations from 0.5 to $5 \mathrm{mg} / \mathrm{dm}^{3}$ in 0.5 increments was calculated and adsorption isotherms were constructed (Fig. 4).

It can be seen from the graphs in Figure 4 that for vermiculite of a smaller fraction, the adsorption is much higher in comparison with the value of adsorption on large fractions at the same equilibrium concentrations. This is due to an increase in the specific surface area of the sorbent and the opening of a larger number of micropores with a reduction in grain size. In general, when the concentration of manganese (II) in the solution increases, the sorption capacity of vermiculite of various sizes, with respect to cations, increases.
The absorption of manganese (II) cations by vermiculite decreases along with the increasing concentration of solutions. This is due to an increase in the ionic strength of the solutions and a decrease in the activity of manganese (II) cations. The maximum extraction of manganese (II) $(>95 \%)$ is observed for vermiculite with a particle size from 0.125 to $2 \mathrm{~mm}$ at the initial concentrations of the model solution in the range of $0.5-1$ $\mathrm{mg} / \mathrm{dm}^{3}$. The data obtained during the series of experiments satisfy the main objective of the research related to the purification of manganesecontaining waste water from the tailing dump.

Research was conducted to study the kinetics of sedimentation of suspended solids and select the preferred sorbent fraction suitable for use in industrial conditions. With a considerable grinding of the starting material, the time of precipitation of the sorbent particles increases, therefore, at the point of wastewater discharge, it is necessary to follow the content of the suspended solids due to the possible removal of the sorbent particles into the water bodies. In order to obtain data for plotting precipitation curves, we used model solutions with the initial concentrations of suspended solids of 2, 3 and $4 \mathrm{~g} / \mathrm{dm}^{3}$. Model solutions were

Table 3. Effect of the particle size of vermiculite on the extraction of manganese (II) cations from the model solution

\begin{tabular}{|c|c|c|c|c|}
\hline Size, $\mathrm{mm}$ & $1-2$ & $0.5-1$ & $0.315-0.5$ & $0.125-0.315$ \\
\hline The recovery of manganese ion (II) on vermiculite, $\%$ & 87 & 95 & 96 & 97 \\
\hline
\end{tabular}

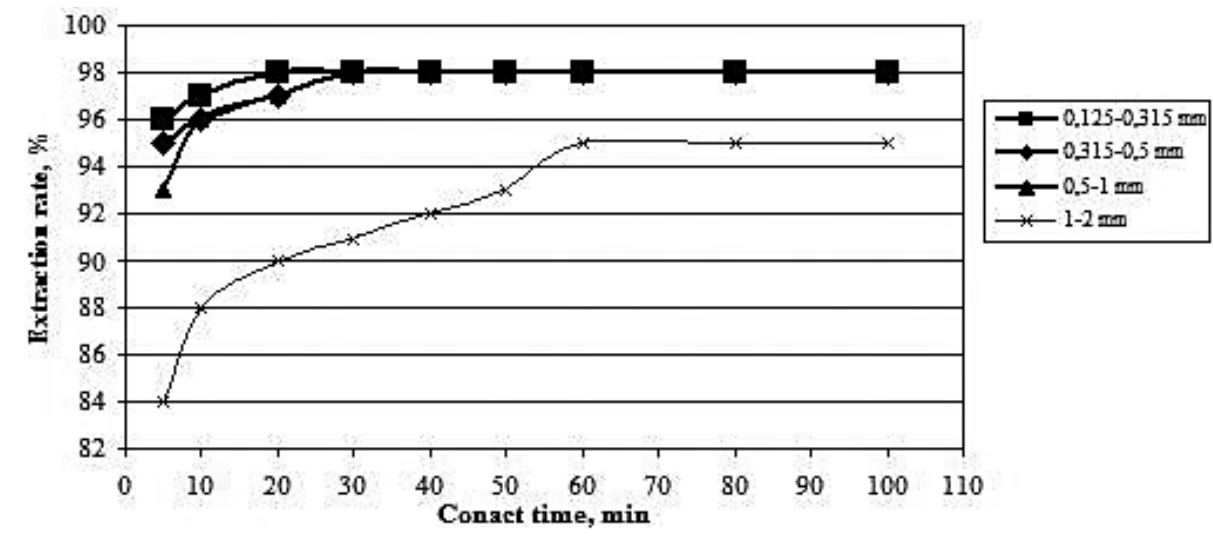

Figure 3. Dependence of the degree of extraction of manganese (II) from the model solution on the contact time for vermiculite of various sizes 


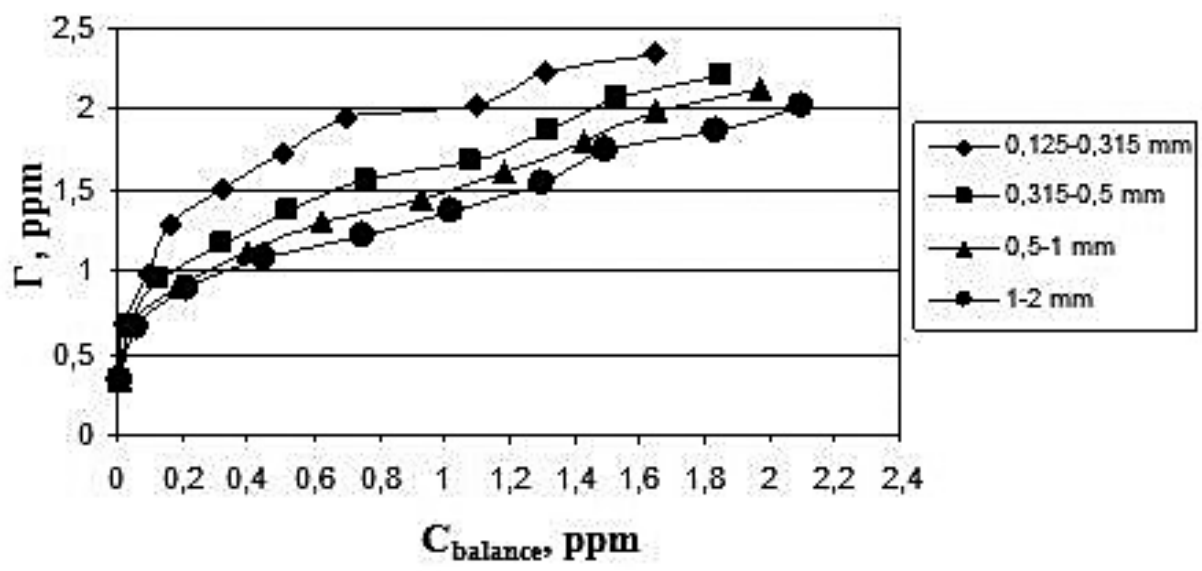

Figure 4. Sorption isotherms of cations of manganese (II) on vermiculite of various sizes depending on the concentration of the initial solution

prepared on the basis of size particulate vermiculite $0.125-0.315 \mathrm{~mm}$. The choice of the fraction is, firstly, due to high purification rates from the data of the experiments carried out, and secondly, because knowing the rate of precipitation of this fraction, one can also judge the efficiency of precipitation of the larger fraction, and vice versa. A graphical representation of the precipitation of comminuted vermiculite with a concentration of $2 \mathrm{~g} / \mathrm{dm}^{3}$ is shown in Figure 5.

Intensive precipitation in each of the three cases was observed in the first 5 hours. Practically, the complete superposition of the graphs of the deposition kinetics obtained during the measurement at the surface and at the bottom of a container with a model solution indicates a uniform deposition of vermiculite particles in height. The analysis of the obtained results allows to draw a conclusion that at the initial concentration of $2 \mathrm{~g} / \mathrm{dm}^{3}$, the concentration of suspended substances of $5.25 \mathrm{mg} / \mathrm{dm}^{3}$ allowed for discharge into the water body under study is reached within 1 day, whereas at the initial concentrations of 3 and $4 \mathrm{mg} / \mathrm{dm}^{3}$ - for 1.5 days.

Taking into account the natural and climatic conditions of the facility, particular attention in the experiment was paid to the study of the effect of solution temperature on the sorption of manganese (II) cations on vermiculite. It is known that the effect of temperature on sorption from aqueous solutions is ambiguous. When sorption occurs on microporous sorbents of substances, the dimensions of which are close to effective pore sizes, the penetration of these substances into the pores depends on their kinetic energy. At a sufficient energy (temperature), the sorbate molecules penetrate into the pore windows and are sorbed; otherwise, only a slight absorption takes place on the surface of the meso- and macropores. In other words, the sorption capacity rises along with the

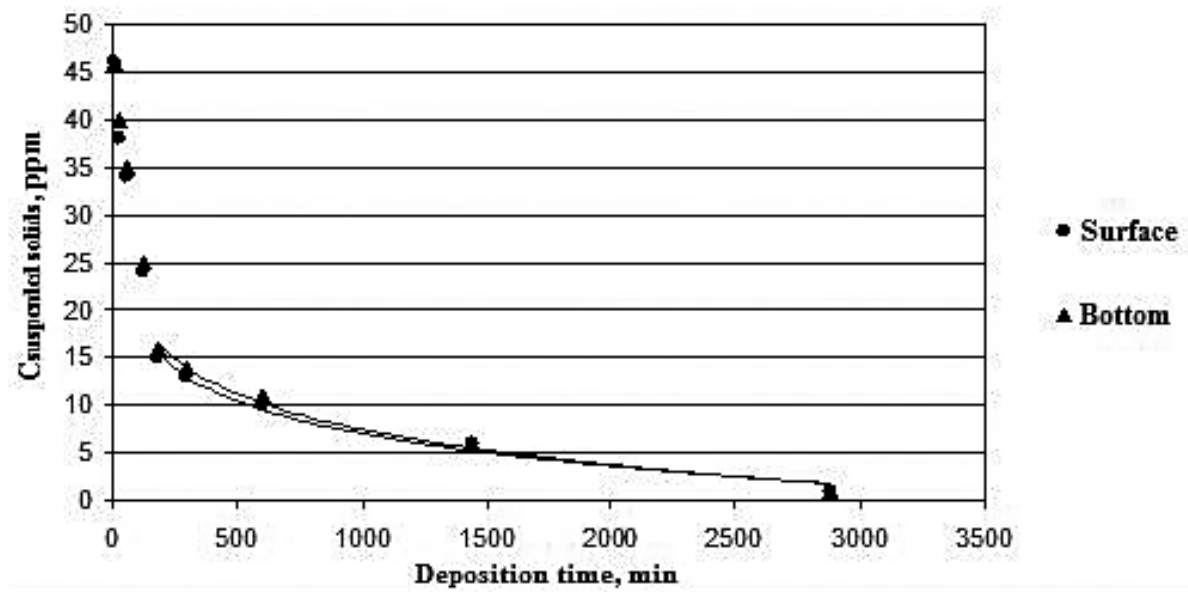

Figure 5. Kinetics of precipitation of crushed vermiculite with a particle size of $0.125-0.315 \mathrm{~mm}$ with an initial concentration in the solution of $2 \mathrm{~g} / \mathrm{dm}^{3}$ 
increasing temperature. At the same time, physical sorption, like any exothermic process, generally deteriorates with increasing temperature. Therefore, the total outwardly recorded manifestation of these two phenomena can have a maximum at a certain temperature.

A series of experiments was carried out to confirm the theoretical studies. Namely, model solutions of manganese (II) were prepared with an initial concentration of $1 \mathrm{mg} / \mathrm{dm}^{3}$, which were kept in a thermostat at temperatures of 20, 15, 10 and $5^{\circ} \mathrm{C}$. Furthermore, freshly prepared solutions of $350 \mathrm{~cm}^{3}$ were mixed with $0.5 \mathrm{~g}$ of vermiculite with a particle size of $0.315-0.500 \mathrm{~mm}$ on a magnetic stirrer for 10 minutes. The results of the experiments showed that with a decrease in temperature by $5^{\circ} \mathrm{C}$, the degree of extraction of manganese (II) from the solution drops by 3 percent. At the same time, the maximum was not recorded at the selected operating temperature range.

The effect of the acidity of the medium, influencing both the form in which the ion under study is located in the solution, and the state of the active centers of the sorbent, was also examined. Theoretical and practical studies have shown that in a weakly alkaline environment, the destruction of vermiculite does not occur regardless of the contact time and concentration of the alkaline solution. In an acidic medium at $\mathrm{pH}=3$, the degree of manganese (II) recovery from the solution is reduced by almost 30 percent, which is explained by the partial destruction of the crystal lattice of vermiculite that adversely affects the sorption capacity of the sorbent. However, the $\mathrm{pH}$ value 3 is significantly lower than the practical acid-base balance of the investigated effluents having a slightly alkaline reaction. Thus, as a result of laboratory studies, it was shown that the high efficiency of purification from manganese, practically to the maximum permissible concentrations, is observed when preparing (disintegrating) vermiculite with the primary use of cutting and shearing forces without additional thermal treatment of the sorbent. The results of the conducted experiments open the prospect of using vermiculite in the process of cleaning large-tonnage manganese-containing wastewater.

\section{CONCLUSION}

In the course of the research, the actual scientific and production problem was solved, which consists in evaluating and reducing the negative impact of the large-tonnage manganese-contain- ing wastewater of the Kovdor Mining and Processing Combine on surface water by developing an ecologically effective and economically advantageous sorption technology for wastewater treatment that allows to:

- increase the efficiency of purification of the investigated wastewater in relation to manganese to 97 percent;

- implement the process of wastewater treatment under static conditions with minimal costs for the modernization of existing treatment facilities;

- realize a new way to increase the sorption capacity of vermiculite by its layer-by-layer disintegration;

- significantly reduce the cost of cleaning as a result of using a natural mineral, i.e. vermiculite, as a sorbent the deposit of which is located in close proximity to the object under study;

- reduce the risk of secondary contamination of treated waters by using safe materials and the absence of chemical treatment of the sorbent;

- improve the ecological situation and the quality of life of the population in the research area.

\section{REFERENCES}

1. Alexandre-Franco M., Albarran-Liso A., GomezSerrano V. 2011. An identification study of vermiculites and micas: Adsorption of metal ions in aqueous solution. Fuel Processing Technology, 92(2), 200-205.

2. Buzuku S., Kraslawski A. 2015. Application of morphological analysis to policy formulation for wastewater treatment. Journal of Mining Institute, Vol. 214, 102-108.

3. Chanturia V., Vaisberg L., Kozlov A. 2014. Promising trends in investigations aimed at all round utilization of mineral raw materials. Obogashchenie Rud, Vol. 2, 2-8.

4. Da Fonseca M., De Oliveira M., Arakaki L. 2006. Removal of cadmium, zinc, manganese and chromium cations from aqueous solution by a clay mineral. Journal of Hazardous Materials, 137(1), 288-292.

5. Maria Valente T. et al. 2012. Pamplona J. Mineralogical attenuation for metallic remediation in a passive system for mine water treatment. Environmental Earth Sciences, 66(1), 39-54.

6. Sis H., Uysal T. 2014. Removal of heavy metal ions from aqueous medium using Kuluncak (Malatya) vermiculites and effect of precipitation on removal. Applied Clay Science, Vol. 95, 1-8.

7. Vaisberg L., Ustinov I. 2014. Modern equipment for mineral processing. Mine surveying and subsurface use, Vol. 4, 45-47. 